\title{
ОТАББРЕВИАТУРНОЕ ОБРАЗОВАНИЕ КАК АКТИВНЫЙ СЛОВООБРАЗОВАТЕЛЬНЫЙ ПРОЦЕСС В COBPEMEHНOM РУССКОМ ЯЗЫКЕ
}

\section{ABBREVIATED EDUCATION AS AN ACTIVE WORD-FORMATION PROCESS IN THE MODERN RUSSIAN LANGUAGE Ma Guanqun}

Summary: The purpose of the study is to describe the features of the formation and functioning of abbreviation derivatives in modern Russian as full-fledged lexical units. The scientific novelty of the work is due to insufficient knowledge of modern abbreviated derivatives in the Russian language. As a result, it was shown that the activity of the word-formation process based on abbreviations is mainly due to extralinguistic factors; the graphic and orthoepic appearance of abbreviation derivatives, the way of their formation, the forms of adoption of borrowed abbreviations and their adaptation in modern Russian depend, obviously, on linguistic factors.

Keywords: from abbreviated derivatives; from abbreviations; word formation; neology.

\author{
Ма Гуаньцюнь \\ аспирант, Московский педагогический \\ государственный университет, \\ maguanqun2018@gmail.com
}

Аннотация: Цель исследования заключается в описании особенностей образования и функционирования отаббреватурных производных в современном русском языке в качестве полноценных лексических единиц. Научная новизна работы обусловлена недостаточной изученностью современных отаббревиатурных производных в русском языке. В результате показано, что активность словообразовательного процесса на основе аббревиатур обусловлена преимущественно экстралингвистическими факторами; графический и орфоэпический облик отаббреватурных производных, способ их образования, формы принятия заимствованных аббревиатур и их адаптация в современном русском языке зависят, очевидно, от лингвистических факторов.

Ключевые слова: отаббревиатурные производные; отаббревиатуры; словообразование; неология.

Задачи исследования определяются поставленной целью: проанализировать закономерности и специфику словообразования с участием аббревиатур, выявить лингвистические и экстралингвистические факторы, влияющие на образование отаббревиатурных производных и их графические, а также орфографические особенности.

При проведении исследования были использованы описательный метод, метод лингвистического наблюдения, метод интерпретации языковых явлений, словообразовательный анализ; для сбора материала был применен метод сплошной выборки.

Теоретическую базу, посвященную аббревиатурам, составляет немало фундаментальных работ, включая труды Д.И. Алексеева [1], Е.Д. Поливанова [9], А.М. Селищева [11], А.М. Сухотина [13], Н.А. Янко-Триницкой [15] и др. На начальных этапах изучения аббревиатур главное внимание ученых было сосредоточено на их статусе - возможности отнесения к полноценным лексемам, не засоряющим русский язык. Однако время и речевая практика разрешили данный вопрос в пользу аббревиатур. Лексическая полноценность аббревиатур более не подвергается сомнению, с них снят «маргинальный» статус, они реабилитированы. Уже Р.И. Могилевский,

\footnotetext{
Предметом исследования являются особенности образования и функционирования отаббревиатур.

Объектом исследования являются отаббревиатурные производные, образованные в основном путем суффиксации и префиксации как от русских, так и от английских аббревиатур.
} разования и фукционирования отаббревиатур. 
И.И. Ройзенон, проследившие динамику развития аббревиатурного фонда русского языка в период с 1918 по 1961 гг., фиксировали интенсивность словообразовательного процесса, связанного с аббревиатурами, отмечая, что появление новых сокращений превалирует над уходом из языка старых [5, с. 363]. В современном русском языке количество аббревиатур, признанных полноправными лексическими единицами, увеличивается, словообразовательная активность их повышается, при этом отаббревиатурные производные носители языка весьма широко используют в речи [14, с. 6], отдавая предпочтение коротким формам [2, с. 32]. «Многочисленные ряды новых производных», образованных от аббревиатур, позволяют рассматривать последние как производящую основу, ведущую себя подобно основе обычного, несокращенного слова [10, с. 13]. Таким образом, на современном этапе развития русского языка аббревиатуры участвуют в словообразовании двумя способами: «первичным» - компрессионным и «вторичным» - производным, «словотворческим» $[14$, с. 16].

Тем не менее вопрос о статусе отаббревиатурных производных нельзя назвать решенным окончательно. В частности, дискуссионными остаются вопросы о причинах, стимулирующих словообразовательный процесс с участием аббревиатур, а также о возможности рассматривать их не как окказионализмы. Кроме того, в современных исследованиях наблюдается терминологическая разрозненность, на что указывает, например, Н.Н. Сафонова, в работе которой рассматриваются деривационные возможности новых аббревиатур; описывается процесс отаббревиации с учетом продуктивных словообразовательных типов русского языка. Исследователь предлагает использовать термин «отаббревиат» (по аналогии с «дериват», «универбат») вместо разнообразных терминологических сочетаний: «отаббревиатурные образования», «отаббревиатурные производные», «аббревемы», «корневые аббревиатуры» [10, с. 17]. Однако полагаем, что этот термин не отражает характера слов, производных от аббревиатур. Под дериватом понимается языковая единица, образованная в процессе деривации, под субстантиватом - языковая единица, образованная в процессе субстативации, под универбатом - языковая единица, образованная в процессе универбации. Таким образом, под аббревиатами можно понимать производные слова, образованные при помощи аббревиации. Но для них уже есть принятый большинством учёных термин «аббревиатура», используемый и в данной работе. Для обозначения слов, производных от аббревиатур, мы будем употреблять термины отаббревиатура и отаббревиатурные производные (образования), понимая их как синонимы.

Практическая значимость работы состоит в возможности использования материалов в преподавании вузовских курсов современного русского литературного языка (разделы «Лексика», «Словообразование»), а также при разработке спецкурсов и спецсеминаров по проблемам неологии, лексикологии и словообразования.

Материалом исследования послужили аббревиатуры и отаббревиатурные образования, извлеченные методом сплошной выборки из текстов СМИ [3], размещенных в открытом доступе в сети «Интернет», из интернет-форумов, блогов, а также из Национального корпуса русского языка [6]; привлеклись также словарные материалы, в частности, из словарей серии «Новое в русской лексике» (ИЛИ РАН) [7; 8] и «Словаря русского языка коронавирусной эпохи» [12].

Лексическая полноценность аббревиатур неоднократно подвергалась сомнению, и некоторое время за ними сохранялся «маргинальный» лексикологический статус. Однако современные исследователи утверждают, что активное использование аббревиатур и их производных «в речевом поведении свидетельствуют о принятии их в качестве полноправных лексических единиц» $[14$, c. 26]. Действительно, в современном русском языке можно отметить интенсивность словообразовательной активности аббревиатур, что находит отражение в различных текстах.

Практически любая аббревиатура, как отмечал Д.И. Алексеев, воспринимается «лексикализированной с потенциальными фонетическими, грамматическими, словообразовательными возможностями» единицей [1, с. 120]. Аббревиатуры на современном этапе развития русского языка являются основой для словотворчества, производящей основой, порождающей ряды дериватов. Словообразование от аббревиации, по мнению Н.Н. Сафоновой, является не менее активным, чем традиционные способы пополнения словарного фонда [10, с. 5]. Во многом это объясняется стремлением языка к речевой экономии, особенно, если учесть, что новые первичные номинации, часто связанные с развитием технологий, состоят из сложных для произнесения словосочетаний, большая часть из которых заимствованы из английского языка (GPS - Global Positioning System; Wi-Fi - Wireless Fidelity; WWW - Web wide world; URL - Uniform Resource Locator).

Благодаря тому что современный русский язык постоянно пополняется новыми аббревиатурами, отражая появление предметов и явлений, можно осмыслить закономерности данного процесса и выявить его специфику.

Ретроспективный анализ аббревиатур и их производных позволяет проследить переход многих рядов отаббревиатур в историзмы (колхоз, колхозник, колхозница; гэбня, гэбэшник, гэбистский, гэбэшница, гэбушник; эссер, эссеровский и пр.). Некоторые аббревиатуры теряют свое 
аббревиатурное значение, но продолжают жить в языке в качестве самостоятельной лексической единицы. Так, аббревиатура ЗИЛ, обозначавшая до недавнего времени Завод имени И.А. Лихачева, сейчас используется в названии культурного центра - «Культурный центр ЗИЛ», построенного на территории бывшего завода. Производные от аббревиатуры ЗИЛ (зиловец, зиловский) при этом стали историзмами.

Анализ отаббревиатурных образований с точки зрения стилистики показывает, что большинство из них принадлежит к низкому (разговорному) стилю. Однако исследователи отмечают и образование от аббревиатур слов, относящихся к нейтральному стилю (IT-технологии, SMS-голосование, ЭКО-оплодотворение и пр.) [10, с. 20].

С точки зрения частеречной принадлежности можно отметить тенденцию образования от аббревиатур имен существительных со значением лица, путем прибавления к основе суффикса -ец- (натовеи, виповеи, вузовеи, омоновец); суффиксов -щик/ик- (пиарщик, гаишник); суффикса -ыш- (замкадыш); и прилагательных, образованных с помощью суффикса -ск- (натовский, виповский, вузовский, омоновский). От некоторых аббревиатур образуются также глаголы (виповать, эсэмэсить, гаишничать), в том числе и видовые пары (nuapumb/nponuapumb).

Переходя к анализу словообразовательного потенциала аббревиатур, отметим, что некоторые ученые признают его лишь за ограниченным кругом наиболее употребительных аббревиатур, подчеркивая окказиональный статус отаббревиатурных производных [10, c. 25]. Впрочем, последние исследования достаточно убедительно доказывают возможность любой аббревиатуры стать родоначальником словообразовательного гнезда [10, с. 25]. Тем не менее можно констатировать, что, во-первых, некоторые отаббревиатурные образования действительно не приживаются в языке, оставаясь окказионализмами, например, к таким словам можно отнести слово гаишевский, лишь единожды представленное в Национальном корпусе русского языка: Драматизм положения был в том, что этим начальником был капитан Павел Петрович Паренаго - наш гаишевский профессор, отлично знавший аспиранта Агреста. [И.С. Шкловский. Эшелон (1984) // «Химия и Жизнь», 1988-1992]) [НКРЯ]; во-вторых, не все аббревиатуры реализуют свой словообразовательный потенциал (ОСАГО, КАСКО). Очевидно, существует ряд лингвистических и экстралингвистических факторов, определяющих словообразовательный процесс с участием аббревиатур.

К лингвистическим факторам, влияющим на появление отаббревиатурных образований, можно отнести благозвучие аббревиатур и их удобопроизносимость, лексемность аббревиатур. Некоторые ученые объяс- няют это изначальной природой аббревиатур, которые образованы от корневых морфем, составляющих семантическое ядро первичной номинации [14, с. 28]. Кроме того, на словообразовательный потенциал той или иной аббревиатуры влияет частотность употребления аббревиатуры, что, в свою очередь, вероятно, отражает значимость обозначаемого социокультурного явления. Иными словами, лингвистические факторы часто связаны с экстралингвистическими. Так, аббревиатура бомж дала начало длинному ряду отаббревиатур, принадлежащих к различным частям речи, обладающих различными коннотациями (бомжик, бомжонок, бомжиха, полубомжичка, бомжатина, бомжатник, бомжовский (бомжевский), побомжовски (по-бомжевски), бомжевать, побомжевать, бомжировать, обомжиться, бомжирующий). Мы можем также предположить, что, приживаясь в языке в качестве полноценной лексемы и теряя свой особый графический облик, аббревиатура начинает существовать как обычное слово, что также является фактором, способствующим раскрытию ее словообразовательного потенциала. Любопытным является то, что носители языка, принадлежащие к более молодому поколению, уже воспринимают подобные аббревиатуры как обычные слова, не задумываясь о ее расшифровке. Помимо аббревиатуры бомж к числу подобных аббревиатур мы относим следующие: ОМОН (омон, омоновцы, по-омоновски, омоновка); $P R$ (пиар) пиарщик, пиарить(ся), распиаренный, pacnuapumb, omnuapumb, nponuapumь(ся); PR-кампания, PR-coбыmue).

В случае с аббревиатурой $P R$ (public relations) можно наблюдать существование в современном русском языке двух ее графических вариантов - аббревиатурного, записанного латиницей $(P R)$, и лексического, записанного кириллицей (пиар). Можно предположить, что в дальнейшем тенденция «тяготения к облику слова» победит, и аббревиатурное начертание будет постепенно вытеснено. Иначе обстоит дело с аббревиатурой $H R$ (human resources). Существуя в современном русском языке и активно участвуя в словообразовании, данная аббревиатура, тем не менее, не теряет аббревиатурного облика (HR-специалист, HR-кампания, HR-директор, $H R$-менеджер). Вероятно, это связано, в первую очередь, с графической «неприглядностью» для «русского глаза» начертания «эйчар». Впрочем, вероятно, существует и иное объяснение: в русской речевой практике существует другое, более понятное наименование, являющееся усечением, - кадровик (сотрудник отдела кадров).

Интересными являются образования от аббревиатур, перенесенных из английского языка путем транслитерации: VIP (вUn), НАTO, ЮНЕСКО и др. Подобные аббревиатуры существуют в языке на правах «корня», так как каждая буква аббревиатуры не несет заложенного первоначально значения, т.е. не имеет внутренней формы. От аббревиатуры НАТО образовались следу- 
ющие производные: натофоб, натовский, натовеи, натовско-американский. Аббревиатура VIP (вun), отражая проблему социальной расслоенности в российском обществе, помимо привычных дериватов типа viр-клиент (вип-клиент) или vір-карта (вип-карта), vip-nерсона, viр-билеты, vip-тусовка, vір-клуб и др. появилась в таких парадоксальных отаббревиатурах, как, например, vip-nаломничество или viр-ДТП. Последний пример интересен тем, что образован путем сложения двух аббревиатур, одна из которых заимствована, записана латиницей и имеет графический облик слова, другая же, в кириллическом написании сохраняет графический облик аббревиатуры.

Следует отметить, что утрата точной расшифровки аббревиатур, содержащихся в основе новообразованных слов, зачастую не влияет на связь с денотатом. Нечленимость аббревиатуры при известном значении, лишают ее статуса аббревиатуры, так как «ее членимость и аббревиатурность относятся уже к диахронии, к этимологии» [11, с. 452]. М.И. Тибилова отмечает, что в некоторых случаях, когда лексическое сокращение, приобретя социальную значимость, начинает употребляться в речи чаще и замещает инициальную номинацию, становясь основным способом номинирования, аббревиатуру следует рассматривать как полноценную лексическую единицу [14, с. 34]. Если отмеченные выше аббревиатуры до сих пор существуют в английском языке в качестве аббревиатур, то, например, аббревиатурное происхождение слова спам (от Spice Ham) даже в английском языке относится к области этимологии. В русском языке данная аббревиатура воспринимается как заимствованная лексема и характеризуется высоким словообразовательным потенциалом: (за)спамить, спамщик, заспамленный и др.

Интересно, что аббревиатуры, появляясь сначала в письменной речи, переходят в устную, а затем возвращаются в письменную часто с измененным написанием (эсэмэсить - аналогично эмчэсник, эмгэушник, т.е. по произношению). Вероятно, подобную перемену облика заимствованной аббревиатуры можно считать признаком принятия ее языком в качестве лексической единицы и «кристаллизации его словообразовательного значения» $[14$, с. 35]. Однако, безусловно, данный процесс требует времени, так как «слово включается в синтагматические и парадигматические связи со словами принимающего языка» постепенно [4, с. 84].

Интересной особенностью некоторых отаббревиатур, включающих в себя заимствованную аббревиатуру и записываемых по схеме «заимствованная аббревиатура - русская лексема», является наличие тавтологии. К таким можно отнести SMS-сообщение, GPS-система, ITтехнологии, VIP-персона. Некоторые русские аббревиатуры также содержат тавтологию (ЭКО-оплодотворение).
Важным экстралингвистическим фактором, определяющим словообразовательный отаббревиатурный процесс, является развитие сфер IT-технологий, рекламы и коммерции. В случае с IT-технологиями, обилие аббревиатур и их производных отражает процесс увеличения как количества новых предметов (гаджетов и аксессуаров к ним), так их частоты использования. Сама аббревиатура IT принесла в современный русский язык такие образования, как IT-технология, IT-бизнес, IT-компания, IT-индустрия, IT-специалист, айтишник (пришедший на смену асушнику от АСУ - автоматизированные системы управления). Многочисленной является линия отаббревиатурных производных от SMS: SMS-сленг; SMS-мошенники; SMS-зависимость; SMSголосование; SMS-сообщение; SMS-объявление; система SMS-контроля; SMS-поиск; SMS-лунатизм; SMS-услуги, служба SMS-знакомств; SMS-индустрия; SMS-запасы; SMS-приколы, SMS-розыгрыши и SMS-загадки; SMS-спам. Последний пример является особенно интересным, если учесть этимологию слова спам: оно состоит из двух заимствованных аббревиатур, первая из которых записывается как аббревиатура и латинскими прописными буквами, вторая же выглядит как лексема. Помимо примеров, в которых аббревиатура SMS фигурирует как графически не освоенная русским языком, встречаются случаи ее русифицированного написания: СМС (смС), смСка, эсэмэска, эсэмэситься. Развитие спутниковых технологий также принесло ряд отаббревиатур: GPS-приемник, GPS-устройство, GPS-набор, GPS-ошейник, GPS-модулъ, GPS-навигатор, GPS-комплект, GPS-адрес, GPS-игра, GPSсистема.

Интересным примером является аббревиатура VK, обозначающая популярную социальную сеть рунета (еще одной аббревиатуры) Вконтакте (Vkontakte). Данная аббревиатура интересна способом образования, представленным слиянием лексемы в форме предложного падежа с предлогом в, а также наличием двух вариантов графического начертания - BK и VK.

Несколько новых отаббревиатур, таких как инстадевочки, инстамамочки, инстаблогер, инстапублика, связанных с названием популярной социальной сети Instagram, образованы путем сращения усеченной английской основы insta и слов, обозначающих различные категории пользователей данной социальной сети.

Среди отаббревиатурных образований, тематически связанных с социальными сетями, можно отметить аббревиатуру ЖЖ (живой журнал), являвшуюся названием довольно популярной в России площадки для публикации постов до прихода в рунет других социальных сетей. С точки зрения начертания интерес представляет аббревиатурное производное от ЖЖ - ЖЖшник - блогер ЖЖ. Графический облик этой отаббревиатуры нетипичен: чаще всего, после аббревиатурного элемента, записан- 
ного заглавными буквами, ставится дефис; либо аббревиатура принимает облик лексемы и записывается по типу вузовец.

Увлечение здоровым образом жизни породило такие аббревиатуры, как 3ОЖ (здоровый образ жизни) и ПП (правильное питание), которые активно участвуют в словообразовательном процессе: зожник, зожница, зожрецепт, зожный; пэпэшки, пn-рецепты (nn-салат, nnторт и др.), пэпэшный.

В начале 2020 года в русском языке появились еще две аббревиатуры, заимствованные из английского языка путем транслитерации - это аббревиатура covid / ковид (Coronavirus Disease) и zoom (Zeroed Output Optical Meter). В силу важности социокультурного явления, обозначаемого аббревиатурой ковид, ярко проявился ее словообразовательный потенциал. В результате в современном русском языке появились такие отаббревиатуры, как ковидобесие, ковид-бумеры, ковид-диссидент, ковидиот, ковидарность, ковидло [12]. Последние три примера интересны тем, что данные отаббревиатуры образованы путем контаминации. Сопутствующий периоду карантина переход на дистанционную профессиональную и учебную деятельность с помощью программы Zoom также привел к появлению в русском языке таких отаббревиатур, как zоотби (зумби), беzоотие (беZОOMuе), зумиться и пр. В большинстве производных от аббревиатур zoom и нескольких производных от аббревиатуры ковид, образованных с помощью контаминации, можно наблюдать элементы языковой игры.

\section{Зак^ючение}

Проведенный анализ отаббревиатурных производных позволяет сделать следующие выводы:

1. ряд современных аббревиатур обладает достаточно высоким словообразовательным потенциалом;

2. словообразовательный потенциал обусловлен экстралингвистическими факторами, прежде всего, важностью социокультурных явлений и предметов, обозначаемых с помощью аббревиатур.

3. наиболее продуктивные способы словообразования на основе аббревиатур - суффиксация, префиксация и сложение;

4. функционирование отаббревиатурных производных детерминируется различиями в функционировании самих аббревиатур, и представлено различными графическими формами: кириллической и латинской, латинско-кириллической, в виде аббревиатуры и в виде лексемы;

5. в настоящее время отсутствует единый орфографический облик отаббревиатур; ряд отаббревиатур имеет несколько вариантов записи (через дефис, в одно слово, с выделением аббревиатуры с помощью заглавных букв);

6. некоторые аббревиатуры, обозначающие наиболее актуальные социокультурные явления, используются в языковой игре.

Перспективы дальнейших исследований мы видим в более подробном изучении семантико-функциональных особенностей отаббревиатур в русском языке последних двух десятилетий.

\section{ЛИТЕРАТУРА}

1. Алексеев Д.И. Сокращенные слова в русском языке. - Саратов: изд-во Саратовского университета, 1979. - 328 с.

2. Горбачевич К.С. Изменение норм русского литературного языка. - Ленинград: Просвещение. Ленингр. отд-ние, 1971. - 270 с.

3. Заразительные неологизмы: русский язык по-своему отвечает на пандемию. Коммерсант. Наука. [Электронный ресypc]. URL: https://bit.ly/361ibyg (дата обращения 20.11.2020)

4. Маринова Е.В. Визуальные неологизмы: новая графика «старых слов» // Вестник ННГУ. Серия «Филология». - Н. Новгород, 2005. - Вып. 1 - С. 127 - 132.

5. Могилевский Р.И., Ройзензон И.И. Письмо в редакцию // Развитие грамматики и лексики современного русского языка: [Сборник статей] / [Под ред. И. П. Мучника и М. В. Панова]; Акад. наук СССР. Ин-т рус. яз. - Москва : Наука, 1964. - 364 с.

6. Национальный корпус русского языка. URL: https://ruscorpora.ru/new/index.html (дата обращения: 14.03.2021)

7. Новое в русской лексике: словарные материалы, 1994: [А - Я] / Российская акад. наук, Ин-т лингвистических исслед.; [Е. А. Левашов и др.] ; под ред. Ю. Ф. Денисенко. - Санкт-Петербург : Дмитрий Буланин, 2006. - 398 с.

8. Новое в русской лексике. Словарные материалы-2019 / Сост. Е.С. Громенко, А.Ю. Кожевников, Н.В. Козловская, Н.А. Козулина, С.Д. Левина, Ю.С. Ридецкая. Отв. ред. Ю.С. Ридецкая / Институт лингвистических исследований РАН. - Санкт-Петербург: Институт лингвистических исследований РАН, 2021. - 110 с.

9. Поливанов Е.Д. Революция и литературные языки Союза ССР / Поливанов Е.Д. Статьи по общему языкознанию. - М., 1968. - С. 186-206.

10. Сафонова Н.Н. Отаббревиатурные образования в современном русском языке... диссертация кандидата филологических наук специальность 10.02.01 - русский язык // Сафонова Наталья Николаевна. [Место защиты Гоу ВПО Тюменский государственный университет]. - Тюмень, 2007. - 223 с.

11. Селищев А.М. Труды по русскому языку. Т. 1. Язык и общество / Состю Б.А. Успенский, 0.В. Никитин. - М.: Языки славянской культуры, 2003.

12. Словарь русского языка коронавирусной эпохи. Сост.Е.С. Громенко, А.Ю. Кожевников, Н.В. Козловская, Н.А. Козулина, С.Д. Левина, В.М. Мокиенко, А.С. Павлова, М.Н. Приемышева, Ю.С. Ридецкая / Ред. коллегия Е.С. Громенко, А.С. Павлова, М.Н. Приемышева (отв. ред.), Ю.С. Ридецкая / Санкт- Петербург: Институт лингвистических исследований РАН, 2021 — 550 с. 
13. Сухотин А.М. Проблема «сокращенных» слов в языках СССР // Письменность и революция. - М., 1933. - 256 с.

14. Тибилова М.И. Аббревиатуры-инновации: системно-описательный и лингвопрагматический аспект ... диссертация кандидата филологических наук / специальность 10.02.01 - русский язык // Тибилова Марина Ираклиевна. [Место защиты ГОУ ВП0 «Астраханский государственный университет]. Астрахань, 2011. -232 c.

15. Янко-Триницкая Н.А. Словообразование в современном русском языке. - М.: Индрик, 2001. - 375 с.

() Ма Гуаньцюнь (maguanqun2018@gmail.com).

Журнал «Современная наука: актуальные проблемы теории и практики»

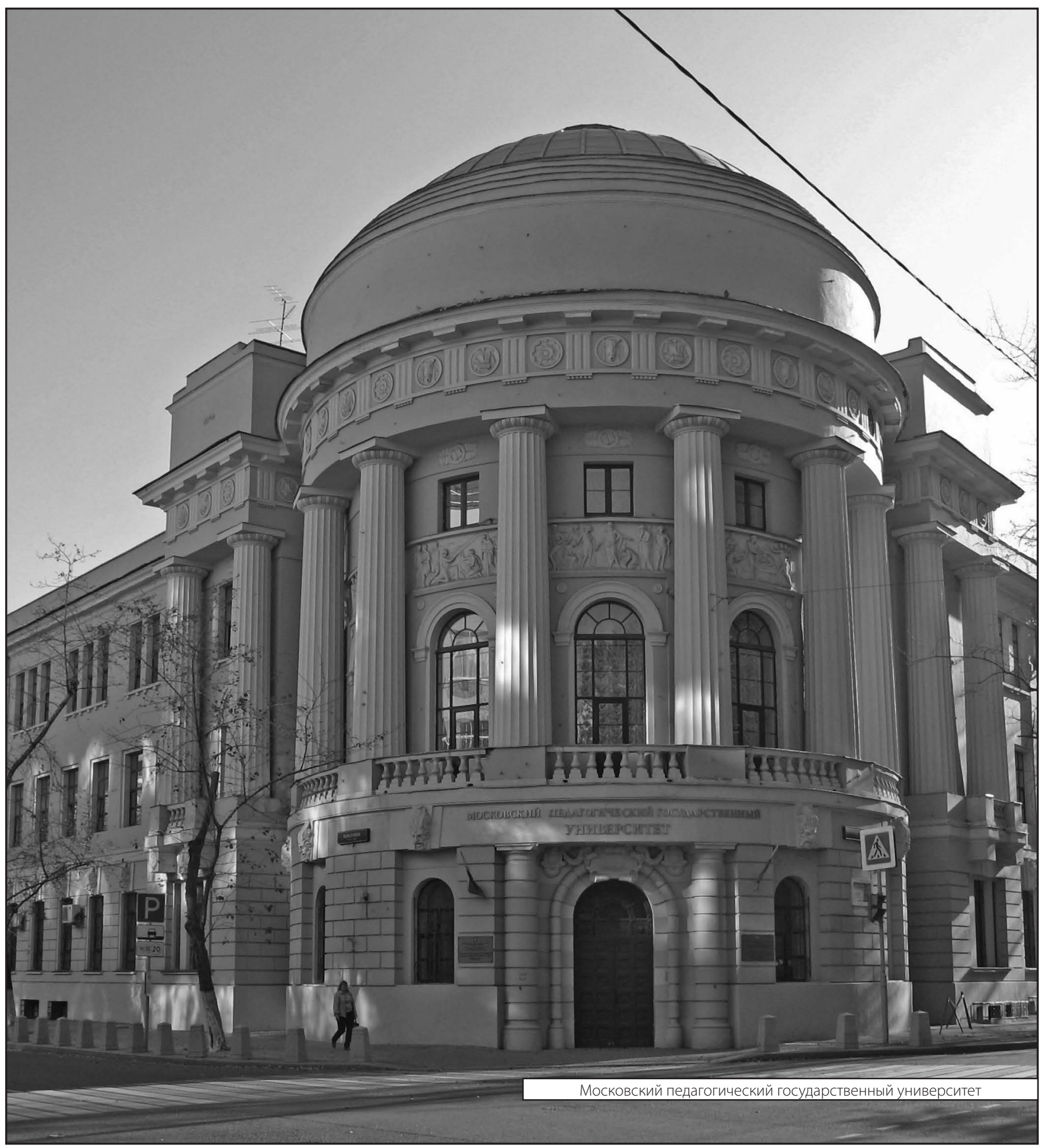

